\title{
Anti-Corrosive Properties and Quantum Chemical Studies of (Benzoxazol) Derivatives on Mild Steel in $\mathrm{HCl}(1 \mathrm{M})$
}

\author{
A. Benzai, ${ }^{1, *}$ F. Derridj, ${ }^{1,2}$ O. Mouadili, ${ }^{3}$ M. El Azzouzi, ${ }^{3}$ M. Kaddouri, ${ }^{3}$ K. \\ Cherrak, ${ }^{3}$ R. Touzani, ${ }^{3,4}$ A. Aouniti, ${ }^{3}$ B. Hammouti, ${ }^{3}$ R. Elatki ${ }^{2}$ and H. Doucet ${ }^{2}$ \\ ${ }^{1}$ Laboratory of Physics and Materials Chemistry (LPCM), Faculty of Sciences, UMMTO, \\ P.O. Box 17, 15000 Tizi Ouzou, Algeria \\ ${ }^{2}$ Laboratory of Catalysis and Organometallics, Institute of Chemical Sciences of Rennes, \\ UMR 6226 CNRS, Campus of Beaulieu, 35042 Rennes, France \\ ${ }^{3}$ Laboratory of Applied Chemistry and Environment -URAC18, Faculty of Science, \\ Mohammed Premier University, P.O. Box 717, 60000 Oujda, Morocco \\ ${ }^{4}$ Laboratory of Applied Chemistry and Environment, COSTE, Faculty of Science, \\ Mohammed Premier University, Oujda-Morocco. \\ *Corresponding author: benz_amel@yahoo.fr
}

Received 04/04/2018; accepted 10/10/2020

https://doi.org/10.4152/pea.202102135

\begin{abstract}
This work is a contribution to the study about the inhibition of mild steel corrosion in a molar hydrochloric acid medium by some benzoxazol derivatives compounds. The study was carried out using gravimetric and electrochemical methods (stationary and transient). We have considered the influence of the inhibitor concentration, the temperature of the medium and the duration of the immersion of the metal sample in the aggressive medium. These studies are complemented with theoretical calculations aimed to correlate the results obtained from experimental measurements using the DFT method. The results obtained in this work through gravimetric and both transient and stationary electrochemical methods showed a satisfied coherence. Theoretical calculations also revealed a good correlation with the experimental results for our compounds.
\end{abstract}

Keywords: Corrosion, mild steel, $\mathrm{HCl}$, Benzoxazole, gravimetric, electrochemical methods and DFT.

\section{Introduction}

Metal corrosion is a major industrial problem that has received a considerable amount of attention. The prevention of corrosion plays an important role in economics and safety. The use of inhibitors is one of the most practical methods to protect metals against corrosion, especially in acidic media ${ }^{1}$. Among these inhibitors, N-heterocyclic compounds are considered to be the most effective corrosion inhibitors. Up to now, many N-heterocyclic compounds with one or several $\mathrm{N}$ heteroatoms have been reported as good corrosion inhibitors for iron or steel in acidic media ${ }^{2}$, such as imidazoline derivatives ${ }^{3-5}$, pyridine derivatives $^{6-8}$, 
pyrimidine derivatives ${ }^{9}$, benzimidazole derivatives ${ }^{10-14}$ and quinoline derivatives ${ }^{15}$.

Pyridinylbenzoxazol compound shows two anchoring sites suitable for surface bonding: the nitrogen atom with $\mathrm{sp}_{2}$ electron pair and the aromatic rings ${ }^{16}$. It is a general assumption that the adsorption of the organic inhibitors at the metal/surface interface is the first step in the mechanism of the inhibitor action. This adsorption produces a uniform film on the metal surface, which reduces or prevents contact with the corrosive medium ${ }^{17}$.

The present paper reports the study of the inhibitive action of the 2-(pyridin-2yl)benzoxazol $\quad\left(\mathrm{L}_{1}\right), \quad$ 2-(benzoxazol-2-yl)quinoline $\quad\left(\mathrm{L}_{2}\right)$ and2-(5(trifluoromethyl)pyridin-2-yl) benzoxazol $\left(\mathrm{L}_{3}\right)$ on the corrosion of steel in molar hydrochloric acid. The steel corrosion behaviour has been evaluated by different techniques: weight loss, potentiodynamic polarisation, EIS measurements and theoretical calculations. The molecular structures of these compounds are presented in Fig. 1.

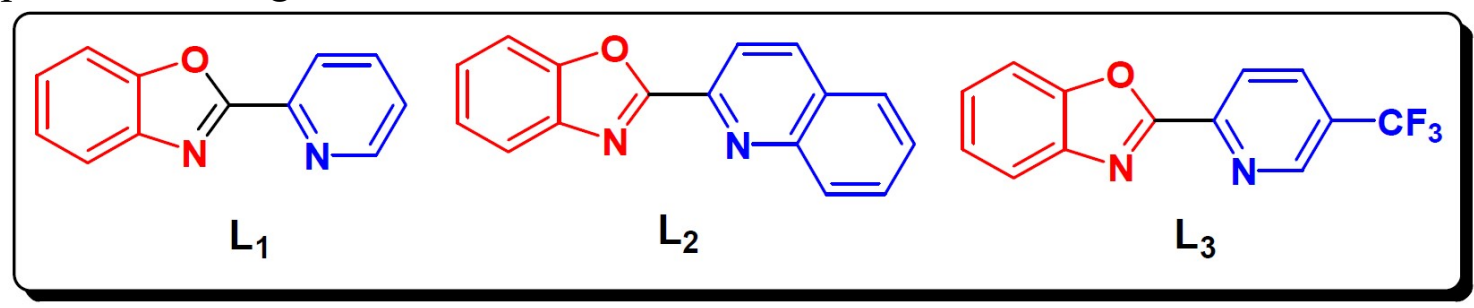

Figure 1. Molecular structure of $\mathrm{L}_{1}, \mathrm{~L}_{2}$ and $\mathrm{L}_{3}$.

\section{Material and methods}

\section{Synthesis of Benzoxazol}

The synthesis of these polyhetero-aromatics compounds using inexpensive and environementaly attractive methods (step and atom economy, limited quantity of toxic substances) is one of the major challenges in organic chemistry.

In this context, the Pyridinylbenzoxazol used in this study was synthetized using direct $\mathrm{C}-\mathrm{H}$ bond activation of benzoxazol catalyzed by palladium, using halo-aryl halides as coupling partner. This method appeared as a greener alternative to classical cross coupling reactions. This procedure has been described by Derridj et al in $2009^{16}$.

To address this challenge, these substances were synthesized by palladium catalysis, using a new organic synthesis method. It allows single-step access to mono-bi and poly-dentate heterocyclic ligands that are more environmentally friendly.This simple and economical procedure allows access to heterocyclic ligands useful in the coordination chemistry ${ }^{17}$ (Fig. 2).

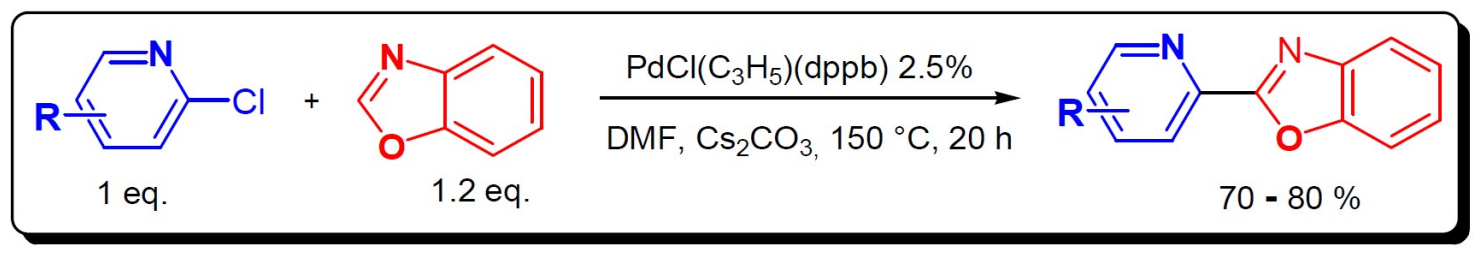

Figure 2. Formula of synthesis of heterocyclic ligands with palladium catalysis. 


\section{Materials and solutions}

In this work we used mild steel with the following chemical composition (in wt\%): 99.21\% Fe; $0.21 \% \mathrm{C}$; $0.38 \% \mathrm{Si} ; 0.09 \% \mathrm{P} ; 0.01 \% \mathrm{Al} ; 0.05 \% \mathrm{~S}$ and $0.05 \%$ $\mathrm{Mn}$. We prepared rectangular samples of the mild steel with the dimensions $2 \times 2$ $\mathrm{x} 0.3 \mathrm{~cm}$ as an electrode for the weight loss measurements. They were polished with $\mathrm{SiC}$ emery paper $(60,180,240,400,600$ and 1200), thoroughly rinsed with bidistilled water and dried by hot air.The aggressive solution was prepared from the dilution of $37 \% \mathrm{HCl}$ analytical grade with bidistilled water ${ }^{18}$.

\section{Results and discussion \\ Weight loss tests \\ Effect of concentration}

The weight loss measurements were performed on mild steel samples immersed for $6 \mathrm{~h}$ in $\mathrm{HCl}(1 \mathrm{M})$ at $308 \mathrm{~K}$, in the absence and presence of benzoxazol as inhibitors. This method is easy to handle and requires only simple equipment. Its principle is based on measuring the weight loss $(\Delta \mathrm{m})$ of the mild steel sample with a total surface $(\mathrm{S})$, during an immersion time $(\mathrm{t})$ in a corrosive solution maintained at a constant temperature. The corrosion rate was described by the following relation:

$$
\mathrm{W}_{\text {corr }}=\frac{\Delta \mathrm{m}}{S_{\mathrm{t}}}
$$

where $\mathrm{W}_{\text {corr }}$ is the corrosion rate in $\mathrm{mg} / \mathrm{h} \mathrm{cm}^{2}, \Delta \mathrm{m}$ is the weight loss in $\mathrm{mg}, \mathrm{S}$ is the total surface in $\mathrm{cm}^{2}$ and $\mathrm{t}$ is the immersion time in $\mathrm{h}$.

The value of the inhibition efficiency was given as follow:

$$
\mathrm{E}_{\mathrm{WL}}(\%)=\frac{W_{\text {Corr }}-W_{\text {Corr }(\text { inh })}}{W_{\text {Corr }}} \times 100
$$

where $\mathrm{W}_{\text {corr }}$ and $\mathrm{W}_{\text {corr(inh) }}$ are the corrosion rates of steel in the absence and presence of the organic compound, respectively.

The values of $\mathrm{E}_{\mathrm{WL}}(\%)$ for three inhibitors are gathered in Table 1.

From the results in Table 1 and Figure 3, we notice that the inhibition efficiency increases with higher concentrations of the inhibitor, whereas the corrosion rate decreases with the increase in $\mathrm{L}_{1}, \mathrm{~L}_{2}$ and $\mathrm{L}_{3}$.

The results show that these compounds have a good inhibition efficiency in the studied medium and that their efficiencies reach $94 \%, 92 \%$ and $88 \%$ for $\mathrm{L}_{2}, \mathrm{~L}_{3}$ and $\mathrm{L}_{1}$, respectively.

We also noted that the addition of the benzene group on the benzoxazole increases the effectiveness of steel inhibition corrosion due to the increased delocalization of the electron density in the molecule, which makes the compound more stable by the mesomeric effect ${ }^{19}$. 


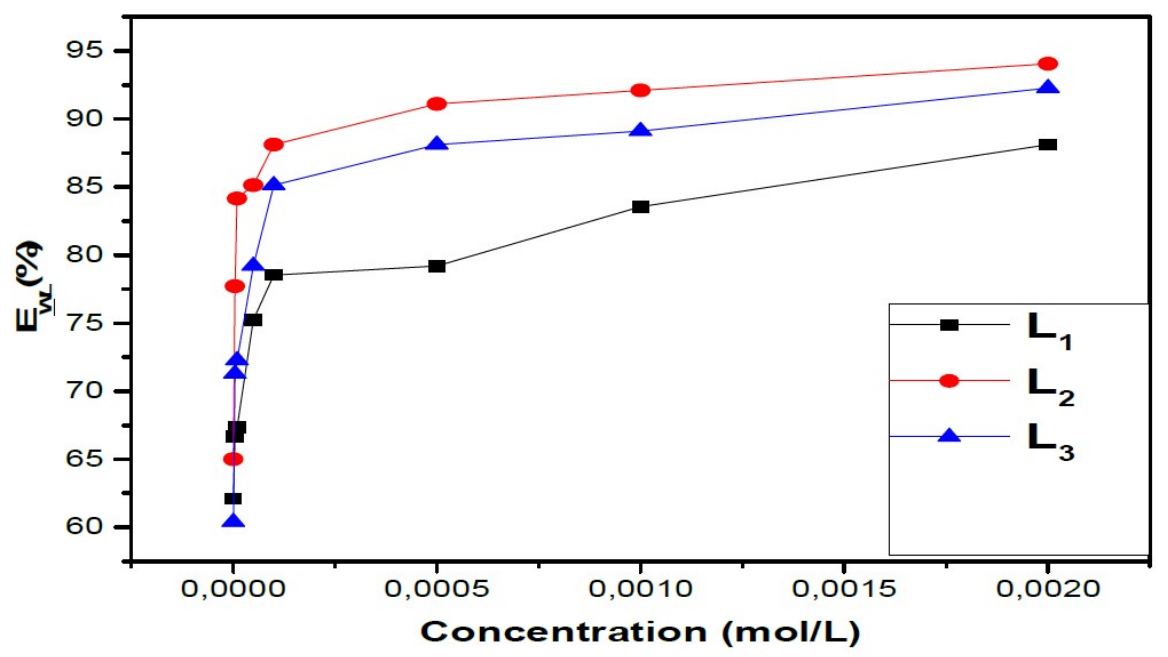

Figure 3. Variation of inhibition efficiencies with inhibitor concentration for mild steel in $1 \mathrm{M} \mathrm{HCl}$ at $308 \mathrm{~K}$.

Table 1. Corrosion rates and inhibitory efficiencies of the three ligands studied at different concentrations, at $308 \mathrm{~K}$.

\begin{tabular}{|c|c|c|c|c|}
\hline Medium & $\begin{array}{l}\text { Conc } \\
\text { (M) }\end{array}$ & $\begin{array}{l}\text { W } \\
\left(\mathrm{mg} \mathrm{h}^{-1} \mathbf{c m}^{-2}\right)\end{array}$ & $\begin{array}{l}\text { E wL } \\
(\%)\end{array}$ & $\boldsymbol{\theta}$ \\
\hline Blank & 1.0 & 1.01 & -- & --- \\
\hline \multirow{8}{*}{ L1 } & $1.10^{-6}$ & 0.38 & 62 & 0.62 \\
\hline & $5.10^{-6}$ & 0.34 & 66 & 0.66 \\
\hline & $1.10^{-5}$ & 0.33 & 67 & 0.67 \\
\hline & $5.10^{-5}$ & 0.25 & 75 & 0.75 \\
\hline & $1.10^{-4}$ & 0.22 & 78 & 0.78 \\
\hline & $5.10^{-4}$ & 0.21 & 79 & 0.79 \\
\hline & $1.10^{-3}$ & 0.20 & 83 & 0.84 \\
\hline & $2.10^{-3}$ & 0.12 & $\underline{88}$ & 0.88 \\
\hline \multirow{8}{*}{ L2 } & $1.10^{-6}$ & 0.35 & $\overline{65}$ & 0.65 \\
\hline & $5.10^{-6}$ & 0.23 & 77 & 0.77 \\
\hline & $1.10^{-5}$ & 0.16 & 84 & 0.84 \\
\hline & $5.10^{-5}$ & 0.15 & 85 & 0.85 \\
\hline & $1.10^{-4}$ & 0.12 & 88 & 0.88 \\
\hline & $5.10^{-4}$ & 0.09 & 91 & 0.91 \\
\hline & $1.10^{-3}$ & 0.08 & 92 & 0.92 \\
\hline & $2.10^{-3}$ & 0.06 & 94 & 0.94 \\
\hline \multirow{8}{*}{ L3 } & $1.10^{-6}$ & 0.40 & 60 & 0.60 \\
\hline & $5.10^{-6}$ & 0.29 & 71 & 0.71 \\
\hline & $1.10^{-5}$ & 0.28 & 72 & 0.72 \\
\hline & $5.10^{-5}$ & 0.21 & 79 & 0.79 \\
\hline & $1.10^{-4}$ & 0.15 & 85 & 0.85 \\
\hline & $5.10^{-4}$ & 0.12 & 88 & 0.88 \\
\hline & $1.10^{-3}$ & 0.11 & 89 & 0.89 \\
\hline & $2.10^{-3}$ & 0.07 & $\underline{92}$ & 0.92 \\
\hline
\end{tabular}




\section{Effect of temperature}

Temperature plays an important role in understanding the inhibitive mechanism of the corrosion process. To assess the effect of temperature on the corrosion and corrosion inhibitive process, weight loss experiments were performed in the temperature range of $308-348 \mathrm{~K}$ in uninhibited acid $(1 \quad \mathrm{M} \quad \mathrm{HCl})$ and inhibited solutions containing $\mathrm{L}_{1}, \mathrm{~L}_{2}$ and $\mathrm{L}_{3}\left(2 \times 10^{-3} \mathrm{M}\right)$.

The corrosion rates and the inhibitory efficiencies of these compounds, as a function of temperature, are given in Table 2.

Table 2. Various corrosion parameters for mild steel in $\mathrm{HCl}$ solution (1 M) in the absence and the presence of $\mathrm{L}_{1}, \mathrm{~L}_{2}, \mathrm{~L}_{3}$ at different temperatures and optimum concentration after $1 \mathrm{~h}$.

\begin{tabular}{|c|c|c|c|c|}
\hline $\begin{array}{l}T \\
\text { (K) }\end{array}$ & Medium & $\begin{array}{l}\mathbf{W} \\
\left(\mathrm{mg} \mathrm{cm}^{-2} \mathrm{~h}^{-1}\right)\end{array}$ & $\boldsymbol{\theta}$ & $\begin{array}{l}E \\
(\%)\end{array}$ \\
\hline \multirow{4}{*}{308} & Blank & 0.18 & - & - \\
\hline & $\mathbf{L}_{1}$ & 0.044 & 0.75 & 75 \\
\hline & $\mathbf{L}_{2}$ & 0.03 & 0.83 & 83 \\
\hline & $\mathbf{L}_{3}$ & 0.041 & 0.77 & 77 \\
\hline \multirow{4}{*}{318} & Blank & 0.19 & - & - \\
\hline & $\mathbf{L}_{1}$ & 0.06 & 0.67 & 67 \\
\hline & $\mathbf{L}_{2}$ & 0.05 & 0.73 & 73 \\
\hline & $\mathbf{L}_{3}$ & 0.058 & 0.69 & 69 \\
\hline \multirow{4}{*}{328} & Blank & 0.25 & - & - \\
\hline & $\mathbf{L}_{1}$ & 0.13 & 0.48 & 48 \\
\hline & $\mathbf{L}_{2}$ & 0.11 & 0.56 & 56 \\
\hline & $\mathbf{L}_{3}$ & 0.126 & 0.50 & 50 \\
\hline \multirow{4}{*}{338} & Blank & 0.52 & - & - \\
\hline & $\mathbf{L}_{1}$ & 0.31 & 0.42 & 42 \\
\hline & $\mathbf{L}_{2}$ & 0.27 & 0.48 & 48 \\
\hline & $\mathbf{L}_{3}$ & 0.3 & 0.43 & 43 \\
\hline \multirow{4}{*}{348} & Blank & 1.12 & - & - \\
\hline & $\mathbf{L}_{1}$ & 0.67 & 0.40 & 40 \\
\hline & $\mathbf{L}_{2}$ & 0.61 & 0.45 & 45 \\
\hline & $\mathbf{L}_{3}$ & 0.65 & 0.42 & 42 \\
\hline
\end{tabular}

In this table we observe an increase in corrosion rates, in the presence and absence of inhibitors, with temperature. Inhibitory efficiency decreases with temperatures between 308 and $348 \mathrm{~K}$. The evolution of the corrosion depends on the nature and structure of the molecules.

\section{Thermodynamic activation parameters}

Several studies ${ }^{20}$ have shown that the decrease in activation energy $\left(E_{a}\right)$, during the addition of the inhibitor to an acidic solution, is attributed to the growth of the metal surface covered by the inhibitor molecule with increasing temperature. Therefore, the rate of corrosion depends on the temperature, according to the Arrhenius equation:

$$
\mathrm{w}=\mathrm{k} \exp \left(-\frac{E_{a}}{R T}\right)
$$


where $\mathrm{k}$ is the pre-exponential factor, $\mathrm{T}$ is the absolute temperature and $\mathrm{R}$ is the universal gas constant. Taking the logarithm of the Arrhenius equation ${ }^{21}$ :

$$
\operatorname{Ln} \mathrm{w}=-\frac{E_{a}}{R T}+\operatorname{Ln} \mathrm{k}
$$

The plot of $\mathrm{Ln} \mathrm{W}=\mathrm{f}(1000 / \mathrm{T})$ (Figure 4) gives a straight line of which slope $\left(-E_{a} / R\right)$ allows us to calculate the activation energy $\left(E_{a}\right)$ in the absence of the inhibitor which is of the order of $56.71 \mathrm{~kJ} \mathrm{~mol}^{-1}$ and which represents the energy barrier that the inhibitor has to cross to be adsorbed onto the surface of the plate.

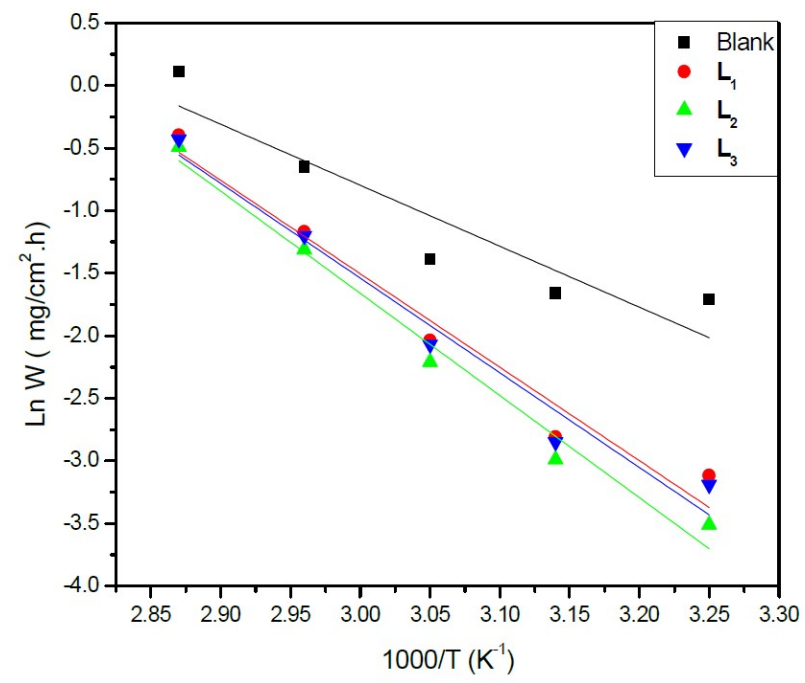

Figure 4. Arrhenius plots of $\mathrm{Ln}(\mathrm{w})$ vs $(1000 / \mathrm{T})$ for steel in a $\mathrm{HCl}$ solution (1 M) in the absence and the presence of $\mathrm{L}_{1}, \mathrm{~L}_{2}$ and $\mathrm{L}_{3}$ at optimum concentration.

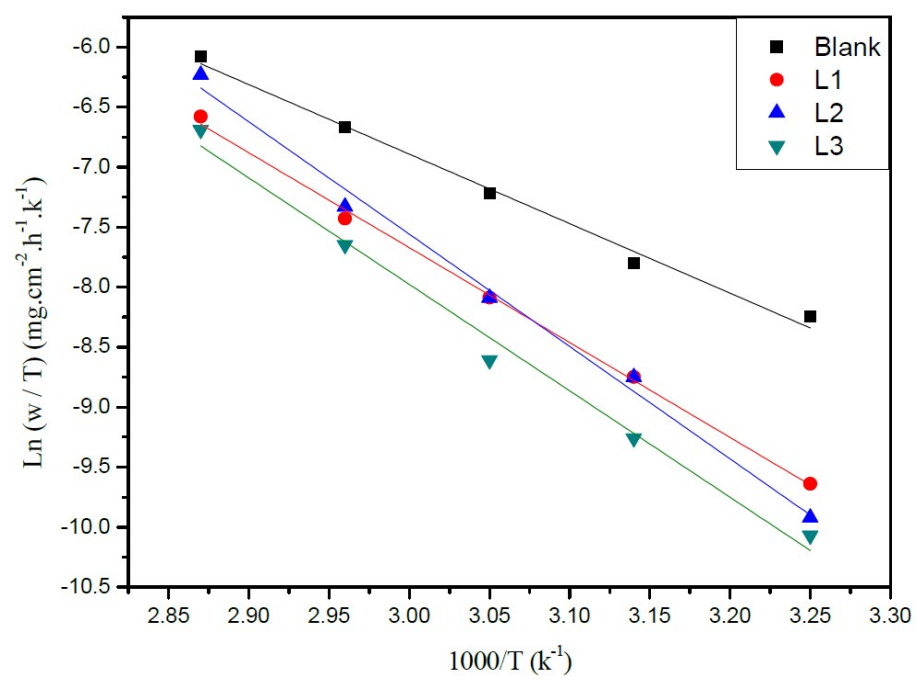

Figure 5. Arrhenius plots of $\mathrm{Ln}(\mathrm{w} / \mathrm{T})$ vs. $1000 / \mathrm{T}$ for steel in a $\mathrm{HCl}$ solution $(1 \mathrm{M})$ in the absence and the presence of $\mathrm{L}_{1}, \mathrm{~L}_{2}$ and $\mathrm{L}_{3}$.

This result is in accordance with the values given in the literature for iron and steel in a $\mathrm{HCl}$ solution $^{22}$. To access the thermodynamic activation characteristics (enthalpy $\left(\Delta \mathrm{H}_{\mathrm{a}}{ }^{\circ}\right)$ and activation entropy $\left(\Delta \mathrm{S}_{\mathrm{a}}{ }^{\circ}\right)$ ), we used the Arrhenius transition equation $^{23}$ : 


$$
\mathrm{W}=\frac{R T}{N h} \exp \left(\frac{\Delta \mathrm{S}_{\mathrm{a}}^{\circ}}{R}\right) \exp \left(-\frac{\Delta \mathrm{Ha}^{\varpi}}{R T}\right)
$$

where $\mathrm{h}$ is the Plank constant and $\mathrm{N}$ is the Avogadro number.

Similarly, Figure 5 shows the variations of $\mathrm{Ln}(\mathrm{W} / \mathrm{T})$ as a function of 1000/T under form of lines with a slope of $-\Delta \mathrm{H}_{\mathrm{a}}{ }^{\circ} / \mathrm{R}$ and the intersection with the ordinate axis is $\left[\mathrm{Ln}(\mathrm{R} / \mathrm{Nh})+\left(\Delta \mathrm{S}_{\mathrm{a}}{ }^{\circ} / \mathrm{R}\right)\right]$. Aditionally, the values of $\Delta \mathrm{H}_{\mathrm{a}}{ }^{\circ}$ and $\Delta \mathrm{S}_{\mathrm{a}}{ }^{\circ}$ can be calculated (Table 3$)$.

Table 3. Values of activation parameters $E_{a}, \Delta H_{a}{ }^{\circ}$ and $\Delta S_{a}{ }^{\circ}$ for mild steel in $1 \mathrm{M} \mathrm{HCl}$ in the absence and presence of different concentrations of $\mathrm{L}_{1}, \mathrm{~L}_{2}$ and $\mathrm{L}_{3}$.

\begin{tabular}{|c|c|c|c|}
\hline Medium & $\begin{array}{l}\mathbf{E}_{\mathrm{a}} \\
\left({\left.\mathrm{kJ} . \mathrm{mol}^{-1}\right)}{ }^{2}\right.\end{array}$ & $\begin{array}{l}\Delta H_{\mathrm{a}}^{\circ} \\
\left(\mathbf{k J} . \mathrm{mol}^{-1}\right)\end{array}$ & $\begin{array}{l}\Delta \mathbf{S}_{\mathrm{a}}^{\circ} \\
\left(\mathbf{J} . \mathbf{m o l}^{-1} \cdot \mathbf{K}^{-1}\right)\end{array}$ \\
\hline Blank & 39.65 & 37.13 & -13.86 \\
\hline $\mathrm{L}_{1}$ & 60.78 & 58.23 & -7.98 \\
\hline $\mathrm{L}_{2}$ & 66.43 & 63.71 & $\begin{array}{l}-6.43 \\
\end{array}$ \\
\hline $\mathrm{L}_{3}$ & 61.58 & 58.96 & $\begin{array}{l}-7.78 \\
\end{array}$ \\
\hline
\end{tabular}

The activation energy value, $E_{a}$, obtained for $L_{2}$ is higher than those obtained for the other investigated compounds, thus confirming the better inhibitory efficiency of $\mathrm{L}_{2}$.

The positive sign of enthalpy, $\Delta \mathrm{H}_{\mathrm{a}}{ }^{\circ}$, indicates the endothermic nature of the steel dissolution process, while the negative entropy, $\Delta \mathrm{S}_{\mathrm{a}}{ }^{\circ}$, reflects the formation of a stable layer of inhibitor on the steel surface ${ }^{23}$.

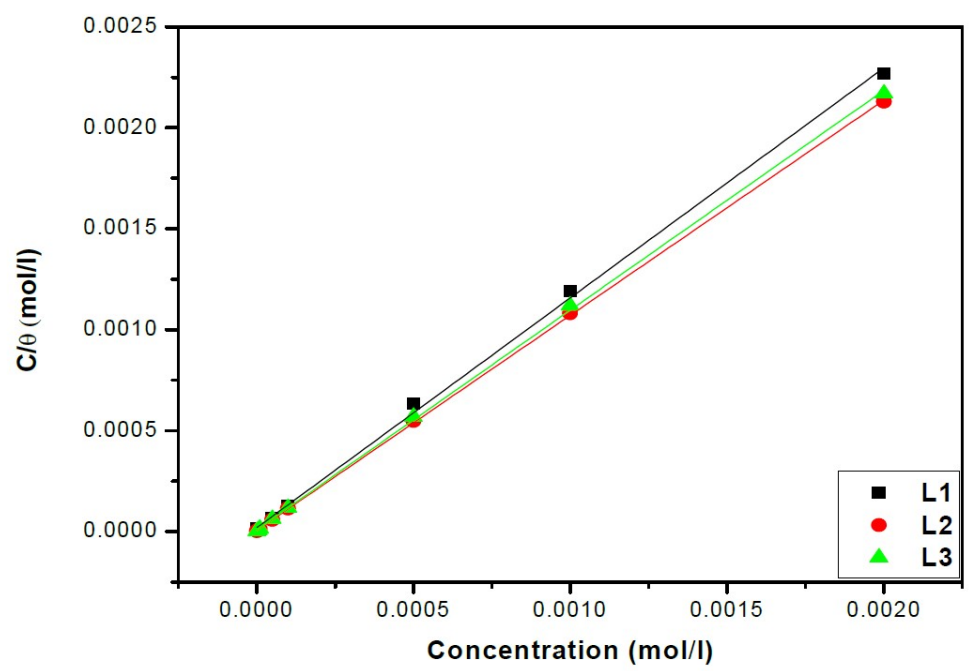

Figure 6. Langmuir adsorption of $\mathrm{L}_{1}, \mathrm{~L}_{2}, \mathrm{~L}_{3}$ on the steel surface in a $\mathrm{HCl}$ solution.

Thermodynamic parameters of adsorption.

Attempts were made to fit surface coverage, $\theta$, to different isotherms including Langmuir, Temkin Frumkin and Freundlich. The organic compound seems to follow well the Langmuir adsorption isotherm written in the rearranged form ${ }^{24}$ :

$$
\frac{C}{\theta}=\frac{1}{K}+\mathrm{C} \quad \text { with } \quad \mathrm{k}=\frac{1}{55.5} \exp \left(-\frac{\Delta G_{a d s}^{2}}{R T}\right)
$$


where $\mathrm{C}$ is the inhibitor concentration, $\mathrm{K}$ is the adsorptive equilibrium constant, and $\Delta \mathrm{G}^{\circ}$ ads is the standard adsorption free energy.

The relationship between $\mathrm{C} / \theta$ and $\mathrm{C}$ presents a linear behaviour at all studied temperatures (Fig. 6) with slopes equal to unity.

Table 4. thermodynamic parameters for the adsorption of $\mathbf{L}_{1}, \mathbf{L}_{2}, \mathbf{L}_{3}$ in $1 \mathrm{M} \mathrm{HCl}$ on the mild steel at $308 \mathrm{~K}$.

\begin{tabular}{|l|l|l|l|l|}
\hline Inhibitors & Slope & $\mathbf{R}^{\mathbf{2}}$ & $\begin{array}{l}\mathbf{K}_{\text {ads }} \\
\left.\mathbf{( M}^{-1}\right)\end{array}$ & $\begin{array}{l}\Delta \mathbf{G}^{\mathbf{a}} \text { ads } \\
\left(\mathbf{k J ~ m o l}^{-\mathbf{1}} \mathbf{)}\right.\end{array}$ \\
\hline $\mathbf{L}_{\mathbf{1}}$ & 1.13 & 0.9989 & 52961.33 & -38.16 \\
\hline $\mathbf{L}_{\mathbf{2}}$ & 1.06 & 0.9991 & 178477.40 & -41.27 \\
\hline $\mathbf{L}_{\mathbf{3}}$ & 1.08 & 0.9996 & 110938.66 & -40.05 \\
\hline
\end{tabular}

From the results given in Table 4, we can conclude that:

The adsorption isotherms allowed us to determine the thermodynamic parameters. The Linear regression coefficient was used to select the suitable isotherm (Table 4). It has been found that the linear regression coefficients are close to unity and all slope are close to 1 .

The high values of adsorption equilibrium constants, $\mathrm{K}_{\mathrm{ads}}$, reflect the high adsorption capacity of these inhibitors onto the mild steel surface. So, the $\mathrm{K}_{\mathrm{ads}}$ value of $\mathrm{L}_{2}$ is superior to those of other studied compounds. Such result suggests that $\mathrm{L}_{2}$ promotes the best recovery of the mild steel surface in comparison with other inhibitors, and, hence, its greater effectiveness in protecting against corrosion $^{25,26}$.

The negative value of the free standard energy of adsorption $\left(\Delta G c_{\text {ads }}\right)$ indicates the spontaneity of the adsorption process of our molecules onto the steel surface $^{27,28}$ and the stability of the formed layer which is due to the strong interaction between the inhibitory molecules and the metal surface ${ }^{29,30}$.

Generally, the standard free energy of $-20 \mathrm{~kJ} \cdot \mathrm{mol}^{-1}$ or less is associated with the electrostatic interaction between the charged molecules and the charged metal surface (physical adsorption); those of $-40 \mathrm{~kJ}^{\mathrm{mol}} \mathrm{m}^{-1}$ or more negative implie a charge or transfer of inhibitory molecules to the metal surface to form covalent bonds with high binding energy (chemisorption) ${ }^{31}$. In this case, the adsorption of $\mathrm{L}_{1}, \mathrm{~L}_{2}$ and $\mathrm{L}_{3}$ is of the chemical type.

\section{Polarization potentiodynamic results}

The potentiodynamic polarization curves were conducted using an electrochemical measurement system, PGZ 100 Potentiostat/Galvanostat, controlled by a PC supported by the Voltamaster 4.0 software. The electrochemical measurements were performed in a conventional three electrode glass cell with mild steel as a working electrode, platinum as auxiliary electrode $(\mathrm{Pt})$ and a saturated calomel electrode used as reference electrode. The working electrode surface was prepared as described above in the gravimetric section. Prior to each electrochemical test, an immersion time of $30 \mathrm{~min}$ was given to allow the stabilization system at corrosion potential. The polarization curves were obtained by changing the electrode potential automatically from -800 to $200 \mathrm{mV} / \mathrm{SCE}$ at a scan rate of $1 \mathrm{mV} \mathrm{s}^{-1}$. The temperature is thermostatically 
controlled at a desired temperature of $\pm 1 \mathrm{~K}$. The percentage protection efficiency, $\mathrm{E}_{\text {Tafel }}(\%)$, is defined as:

$$
\mathrm{E}_{\text {Tafel }}(\%)=\frac{I_{\text {corr }}-I_{\text {corr }(i n h)}}{I_{\text {corr }}} \times 100
$$

where $\mathrm{I}_{\text {corr }}$ and $\mathrm{I}_{\text {corr(inh) }}$ are the corrosion current densities for the steel electrode in the uninhibited and inhibited solutions, respectively ${ }^{32}$.

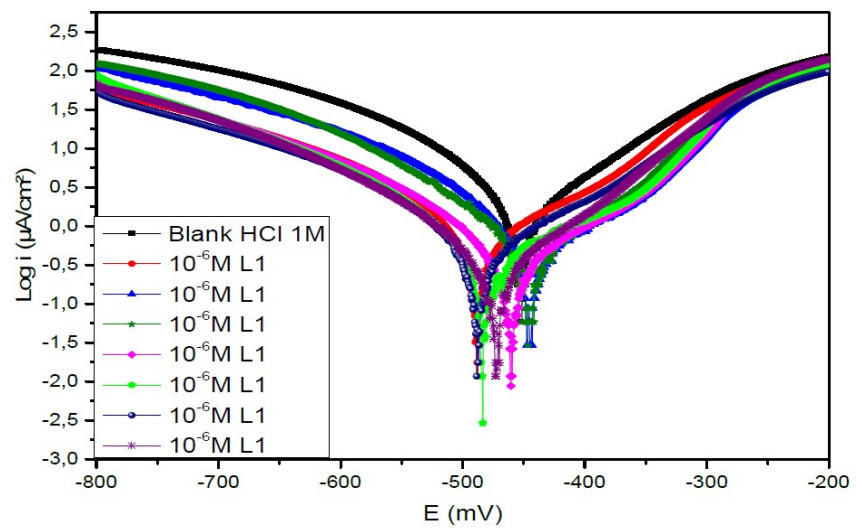

Figure 7a. Polarisation curves of the mild steel in $1 \mathrm{M} \mathrm{HCl}$ for various concentrations of $\mathrm{L}_{1}$ at $308 \mathrm{~K}$.

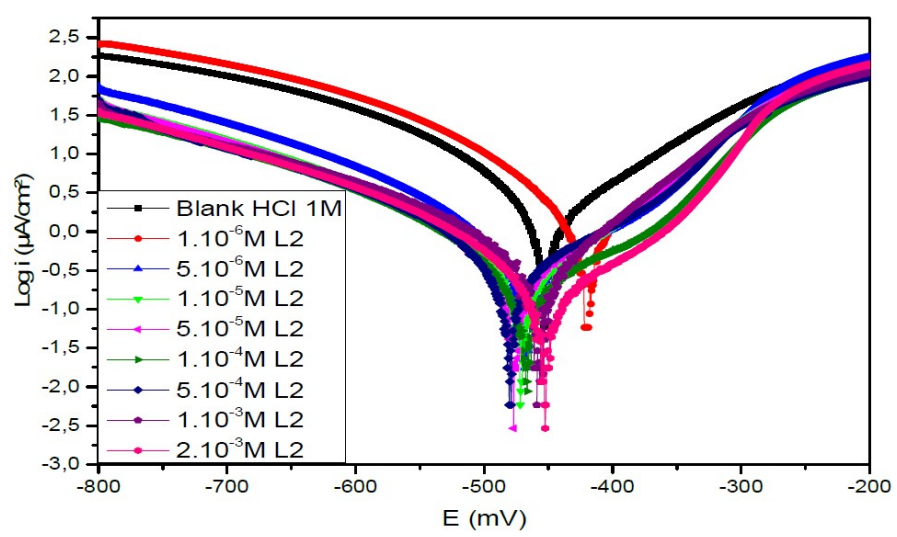

Figure $7 \mathbf{b}$. Polarisation curves of the mild steel in $1 \mathrm{M} \mathrm{HCl}$ for various concentrations of $\mathrm{L}_{2}$ at $308 \mathrm{~K}$.

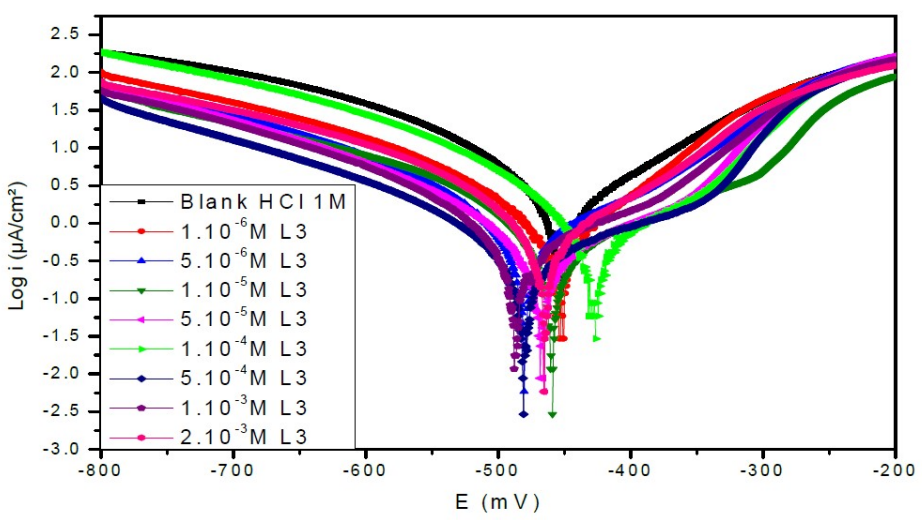

Figure 7c. Polarisation curves of the mild steel in $1 \mathrm{M} \mathrm{HCl}$ for various concentrations of $\mathrm{L}_{3}$ at $308 \mathrm{~K}$. 
Figs. $7 \mathrm{a}, 7 \mathrm{~b}$ and $7 \mathrm{c}$ represent the potentiodynamic polarization curves for carbon steel in $1.0 \mathrm{M} \mathrm{HCl}$, in the absence and presence of various concentrations of this inhibitor.Table 5 shows the electrochemical corrosion parameters, i.e., the corrosion potential $\left(\mathrm{E}_{\mathrm{corr}}\right)$, cathodic and anodic Tafel slopes $\left(\beta_{\mathrm{c}}, \beta_{\mathrm{a}}\right)$, corrosion current density ( $\mathrm{I}_{\text {corr }}$ ), obtained by extrapolation of the Tafel lines, and the inhibition efficiency ( $\left.\mathrm{E}_{\text {Tafel }} \%\right)$.

Table 5. Polarization data of the mild steel in $1 \mathrm{M} \mathrm{HCl}$, without and with addition of inhibitors, at $308 \mathrm{~K}$.

\begin{tabular}{|c|c|c|c|c|c|c|}
\hline Medium & $\begin{array}{l}\text { Conc } \\
\text { (M) }\end{array}$ & $\begin{array}{l}-E_{\text {corr }} \\
(\mathbf{m V} / \mathbf{S C E})\end{array}$ & $\begin{array}{l}\text { Icorr } \\
\left(\mu \mathrm{A} / \mathbf{c m}^{2}\right)\end{array}$ & $\begin{array}{l}-\beta_{c} \\
\text { (mv/dec) }\end{array}$ & $\begin{array}{l}\beta_{a} \\
\text { (mv/dec) }\end{array}$ & $\begin{array}{l}\text { ETafel } \\
(\%)\end{array}$ \\
\hline $\mathrm{HCl}$ & 1 & 453.7 & 1782 & 88.5 & 126.7 & -- \\
\hline \multirow{8}{*}{ L1 } & $2.10^{-3}$ & 495.8 & 227.7 & 82.3 & 118.7 & 87 \\
\hline & $10^{-3}$ & 473.4 & 259.5 & 82.5 & 100.4 & 85 \\
\hline & $5.10^{-4}$ & 488.7 & 303.1 & 67.3 & 91.2 & 83 \\
\hline & $10^{-4}$ & 485.2 & 399 & 85.7 & 219.6 & 78 \\
\hline & $5.10^{-5}$ & 461.5 & 410.4 & 100.9 & 161.9 & 77 \\
\hline & $10^{-5}$ & 446.6 & 470.5 & 80 & 117 & 74 \\
\hline & $5.10^{-6}$ & 445.9 & 581.6 & 82.5 & 179.2 & 68 \\
\hline & $10^{-6}$ & 489.3 & 585 & 85.5 & 130.1 & 67 \\
\hline \multirow{8}{*}{ L2 } & $2.10^{-3}$ & 453.4 & 128.5 & 73.9 & 110.2 & 93 \\
\hline & $10^{-3}$ & 459.3 & 143.3 & 51.4 & 56.5 & 92 \\
\hline & $5.10^{-4}$ & 481.2 & 192.4 & 67.8 & 91.8 & 89 \\
\hline & $10^{-4}$ & 468.2 & 218.7 & 97.9 & 169.5 & 87 \\
\hline & $5.10^{-5}$ & 478.2 & 269.3 & 92.9 & 123.8 & 85 \\
\hline & $10^{-5}$ & 472.4 & 305.8 & 100.4 & 131.3 & 83 \\
\hline & $5.10^{-6}$ & 468.8 & 387.3 & 90.8 & 151 & 79 \\
\hline & $10^{-6}$ & 420.8 & 737.9 & 61.2 & 78.2 & 60 \\
\hline \multirow{8}{*}{$\mathbf{L 3}$} & $2.10^{-3}$ & 465.9 & 179.1 & 31.7 & 34.4 & 90 \\
\hline & $10^{-3}$ & 488.1 & 204.9 & 46.9 & 75 & 89 \\
\hline & $5.10^{-4}$ & 482 & 234.8 & 79.9 & 127.8 & 87 \\
\hline & $10^{-4}$ & 429.2 & 295.8 & 45.1 & 85.7 & 84 \\
\hline & $5.10^{-5}$ & 468.6 & 388.7 & 95.8 & 165.9 & 79 \\
\hline & $10^{-5}$ & 460.6 & 428.4 & 82.9 & 165.8 & 77 \\
\hline & $5.10^{-6}$ & 481.5 & 617.8 & 95 & 149.6 & 67 \\
\hline & $10^{-6}$ & 454.4 & 698 & 96.9 & 96.9 & 62 \\
\hline
\end{tabular}

Examination of the results in Table 5 shows that the corrosion current density decreases as the concentration of the tested products increases and this is consistent with the increase in the inhibitory efficiency of our inhibitors proportionally to their concentration.

In the anodic domain, we note that the presence of $\mathrm{L}_{1}, \mathrm{~L}_{2}$ and $\mathrm{L}_{3}$ results in a decrease in oxidation current densities. According to the literature ${ }^{45}$, an inhibitor could be classified as of the mixed-type when the change in the values of the corrosion potential, $\mathrm{E}_{\text {corr, }}$ is lower than $85 \mathrm{mV}$. In our case, the largest displacement exhibited by the inhibitors was $40 \mathrm{mV}$; this result clearly indicates that these inhibitors have a cathodic and anodic effect. In addition, the $\beta \mathrm{a}$ and $\beta \mathrm{c}$ values of each inhibitor were found to change with the inhibitor concentration. 
Therefore, they can be classified as mixed inhibitors in a hydrochloric medium (1 M).

The addition of the compounds $\mathrm{L}_{1}, \mathrm{~L}_{2}$ and $\mathrm{L}_{3}$ has no remarkable influence on the Tafel slope, in comparison with the results obtained in the case of the acid alone. As a result, the hydrogen reduction reaction at the steel surface is not modified and is carried out by a pure activation mechanism ${ }^{33}$, and the inhibitors first adsorb onto the steel surface, before acting by simply blocking its active sites.

\section{Electrochemical Impedance Spectroscopy (EIS)}

In order to confirm the results extracted from the polarization curve and to gain more information on the corrosion mechanisms, electrochemical impedance spectroscopy (EIS) measurements were carried out with sinusoidal potential waves of $10 \mathrm{mV}$ amplitude, with frequencies ranging from $100 \mathrm{kHz}$ to $10 \mathrm{mHz}$ at the corrosion potential. The impedance diagrams are given in the Nyquist representation. The charge transfer resistance $\left(\mathrm{R}_{\mathrm{ct}}\right)$ was determined from Nyquist plots and the double layer capacitance $\left(\mathrm{C}_{\mathrm{dl}}\right)$ was calculated from the constant phase element (CPE) parameters of the equivalent circuit determined by using Zview software. In this case, the percentage protection efficiency $\left(E_{z} \%\right)$ is calculated from the charge transfer resistance $\left(\mathrm{R}_{\mathrm{ct}}\right)$ :

$$
\mathrm{E}_{\mathrm{z}}(\%)=\frac{R_{c t}^{i}-R_{c t}^{\mathrm{o}}}{R_{c t}^{i}} \times 100
$$

where $R_{c t}^{i}$ and $R_{c t}^{0}$ are the charge transfer resistance in presence and in absence of the inhibitor, respectively.

Double-layer capacitance $\left(\mathrm{C}_{\mathrm{dl}}\right)$ values were calculated using the following equation ${ }^{34}$ :

$$
\mathrm{C}_{\mathrm{dl}}=\frac{1}{2 \pi F_{\max } R_{c t}}
$$

where $F_{\max }$ is the frequency at which the imaginary component of the impedance is greatest. The semicircle corresponds to a capacitive loop in the obtained electrochemical impedance diagrams. Deviations from a perfectly circular shape indicate the frequency dispersion of the interfacial impedance ${ }^{35}$.

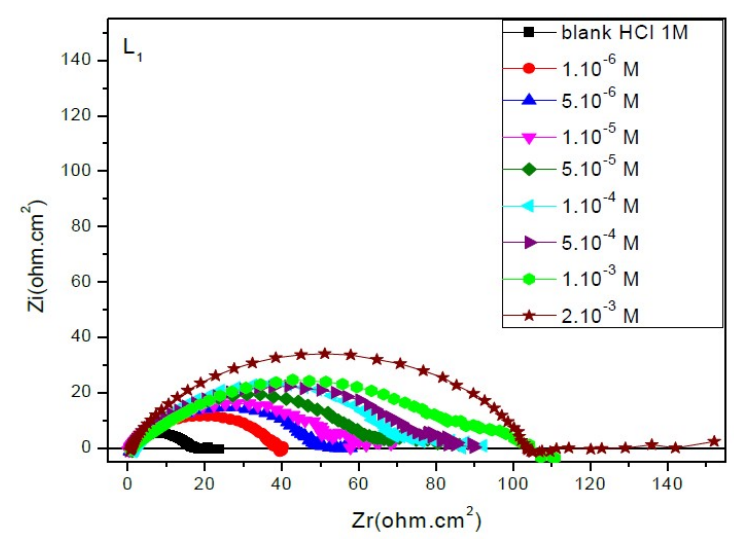

Figure 8a. The Nyquist curves for mild steel in $1 \mathrm{M} \mathrm{HCl}$ for selected concentrations of $\mathrm{L}_{1}$ at $308 \mathrm{~K}$. 


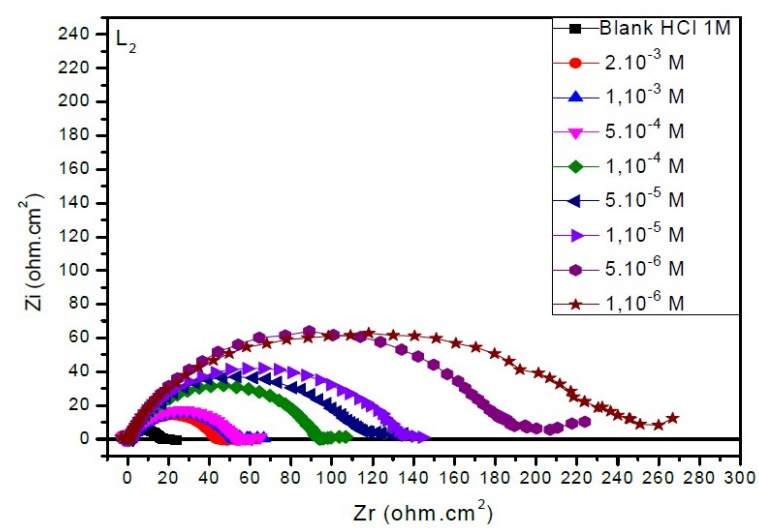

Figure 8b. The Nyquist curves for mild steel in $1 \mathrm{M} \mathrm{HCl}$ for selected concentrations of $\mathrm{L}_{2}$ at $308 \mathrm{~K}$.

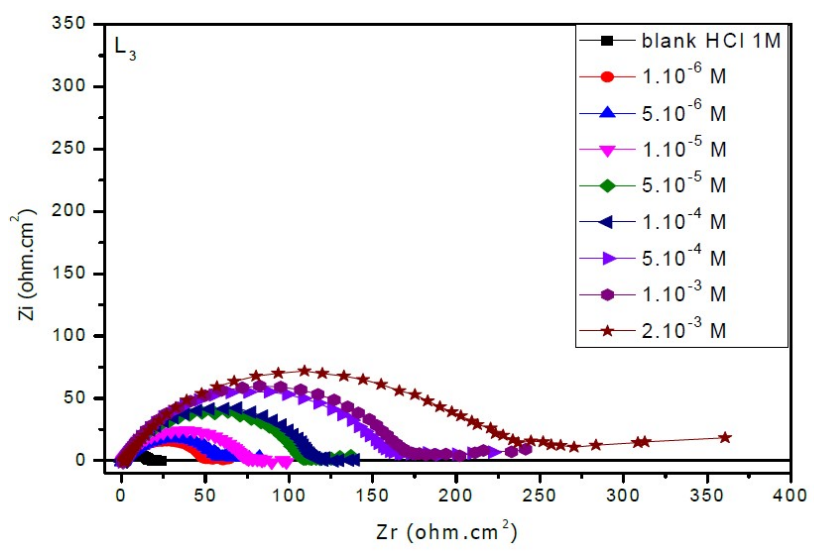

Figure 8c. The Nyquist curves for mild steel in $1 \mathrm{M} \mathrm{HCl}$ for selected concentrations of $\mathrm{L}_{3}$ at $308 \mathrm{~K}$.

The EIS diagrams of mild steel in $1 \mathrm{M} \mathrm{HCl}$ in the presence of $\mathrm{L}_{1}, \mathrm{~L}_{2}$ and $\mathrm{L}_{3}$ at different concentrations are shown in Fig. 8a, 8b and 8c, respectively.

The electrochemical parameters and the inhibitory efficiency for benzoxazole derivatives at different concentrations obtained from EIS measurements are gathered in Table 6.

The analysis of Table 6 shows that the values of $R_{c t}$ and inhibitory efficiency, $\mathrm{E}_{Z}(\%)$, become more important with an increasing concentration of the three benzoxazol derivatives. The double layer capacity, $\mathrm{C}_{\mathrm{dl}}$, decreases with a raise in the inhibitor concentration; this is due to the inhibitor molecules adsorption onto the metal surface, causing the decrease in their active surface. Therefore, the more the inhibitor is adsorbed, the more the thickness of the organic deposit is greater and, simultaneously, the double layer capacity decreases according to the expression of $\mathrm{C}_{\mathrm{dl}}$ presented in Helmotz model:

$$
C_{d l}=\frac{\varepsilon_{0} \varepsilon}{e} S
$$

where $\mathrm{e}$ is the thickness of the deposit, $\mathrm{S}$ is the electrode surface, $\varepsilon_{0}$ is the permittivity of the medium and $\varepsilon$ is the dielectric constant. This change in $\mathrm{R}_{\mathrm{ct}}$ and $\mathrm{C}_{\mathrm{dl}}$ is probably due to the displacement of water molecules by the $\mathrm{Cl}^{-}$ions of the 
acid and to the adsorption of organic molecules onto the metal surface, thus decreasing the metal dissolution rate and reduction of $\mathrm{H}^{+}$protons ${ }^{36}$.

Table 6. EIS parameters for the corrosion of mild steel in $1 \mathrm{M} \mathrm{HCl}$ containing $\mathrm{L}_{1}, \mathrm{~L}_{2}$ and $\mathrm{L}_{3}$ at $308 \mathrm{~K}$.

\begin{tabular}{|c|c|c|c|c|}
\hline Medium & $\begin{array}{l}\text { Conc } \\
\text { (M) }\end{array}$ & $\begin{array}{l}\text { Rct } \\
\left(\Omega \mathbf{c m}^{2}\right)\end{array}$ & $\begin{array}{l}\mathrm{C}_{\mathrm{dl}} \\
\left(\mu \mathrm{F} / \mathrm{cm}^{2}\right)\end{array}$ & $\begin{array}{l}\text { Ez } \\
(\%)\end{array}$ \\
\hline $\mathrm{HCl}$ & 1 & 17 & 192 & -- \\
\hline \multirow{8}{*}{ L1 } & $2.10^{-3}$ & 104.5 & 19.6 & 84 \\
\hline & $10^{-3}$ & 94.58 & 29.7 & 82 \\
\hline & $5.10^{-4}$ & 79.61 & 50 & 78 \\
\hline & $10^{-4}$ & 72.08 & 67.8 & 76 \\
\hline & $5.10^{-5}$ & 65.08 & 81.7 & 74 \\
\hline & $10^{-5}$ & 56.7 & 106.8 & 70 \\
\hline & $5.10^{-6}$ & 49.56 & 124.4 & 65 \\
\hline & $10^{-6}$ & 38.83 & 146.2 & 56 \\
\hline \multirow{8}{*}{ L2 } & $2.10^{-3}$ & 240 & 15.1 & 94 \\
\hline & $10^{-3}$ & 187.2 & 35.2 & 91 \\
\hline & $5.10^{-4}$ & 135.2 & 42.5 & 87 \\
\hline & $10^{-4}$ & 116 & 51 & 85 \\
\hline & $5.10^{-5}$ & 94.2 & 59.1 & 82 \\
\hline & $10^{-5}$ & 54 & 67.8 & 69 \\
\hline & $5.10^{-6}$ & 52.45 & 98 & 67 \\
\hline & $10^{-6}$ & 44 & 138.2 & 61 \\
\hline \multirow{8}{*}{ L3 } & $2.10^{-3}$ & 235 & 44.2 & 93 \\
\hline & $10^{-3}$ & 172.8 & 54 & 90 \\
\hline & $5.10^{-4}$ & 162 & 71.3 & 89 \\
\hline & $10^{-4}$ & 116.3 & 72.8 & 85 \\
\hline & $5.10^{-5}$ & 108.7 & 94.8 & 84 \\
\hline & $10^{-5}$ & 75.5 & 102.4 & 77 \\
\hline & $5.10^{-6}$ & 61 & 114.9 & 72 \\
\hline & $10^{-6}$ & 51.5 & 161.7 & 67 \\
\hline
\end{tabular}

\section{Quantum chemical calculations}

To correlate the experimental data obtained from the weight loss, the quantum indices of $\mathrm{L}_{1}, \mathrm{~L}_{2}$ and $\mathrm{L}_{3}$ are computed using B3LYP/6-31G $(\mathrm{d}, \mathrm{p})$. For this purpose, the program Gaussian $09 \mathrm{w}^{37}$ was used with an optimization of the geometry.

According to the frontier molecular orbital theory (FMO) of chemical reactivity, the transition of electrons is due to the interaction between the highest occupied molecular (HOMO), the lowest unoccupied molecular orbital (LUMO) of the

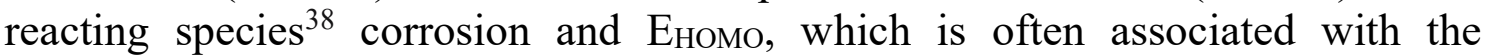
electron-donating ability of the molecule. The literature shows that the adsorption of the inhibitor onto the metal surface can occur on the basis of donor-acceptor interactions between the $\pi$-electrons of the heterocycle compound and the vacant d-orbitals of the metal surface atoms ${ }^{39}$. The energy of ELUMO indicates its ability to accept electrons. The high values of $\mathrm{E}_{\text {НОмо }}$ are likely to indicate a tendency of 
the molecule to donate electrons to appropriate acceptor molecules with low energy and empty molecular orbital. A low $\Delta \mathrm{E}$ value should facilitate the adsorption of the molecule and therefore cause an increase in the inhibitory efficiency $^{40}$. According to Koopmans' theorem ${ }^{41}$, the energies of HOMO and LUMO of the inhibitors are related to the ionization potential, I, and the electronic affinity, A, by the following relations:

$$
\mathrm{I}=-\mathrm{E}_{\text {HOMO }} \text { et } \mathrm{A}=-\mathrm{E}_{\text {LUMO }}
$$

The absolute electronegativity $(\chi)$, and the absolute hardness $(\eta)$ of the inhibitor molecule are given by ${ }^{42}$.

$$
\chi=\frac{\mathrm{I}+\mathrm{A}}{2} \quad \text { et } \quad \eta=\frac{\mathrm{I}-\mathrm{A}}{2}
$$

The fraction of transferred electrons $(\Delta \mathrm{N})$, non-binding doublets of the nitrogen atom and / or electrons $\pi$, to the $\mathrm{d}$ orbital of the Fe atom is given by ${ }^{40}$ :

$$
\Delta \mathrm{N}=\frac{\chi_{\mathrm{Fe}}-\chi_{\mathrm{inh}}}{2\left(\eta_{\mathrm{Fe}}+\eta_{\mathrm{inh}}\right)}
$$

In order to calculate the fraction of transferred electrons $(\Delta N)$, a theoretical value of the electronegativity of iron equal to $\gamma_{\mathrm{Fe}}=7 \mathrm{eV}$ and an overall hardness $\eta_{\mathrm{Fe}}=0$ were used ${ }^{40}$. Among the calculated parameters, we cite the HOMO energy of $\mathrm{E}_{\text {HOMO, }}$ LUMO energy of ELUMо, HOMO-LUMO energy gap, $\Delta \mathrm{E}_{\text {gap, }}$, and dipole moment, $\mu$. The quantum-chemical parameters in the neutral form are given in Table 7.

The optimized minimum energy structure of $\mathrm{L}_{1}, \mathrm{~L}_{2}$ and $\mathrm{L}_{3}$ is shown in Fig.9.

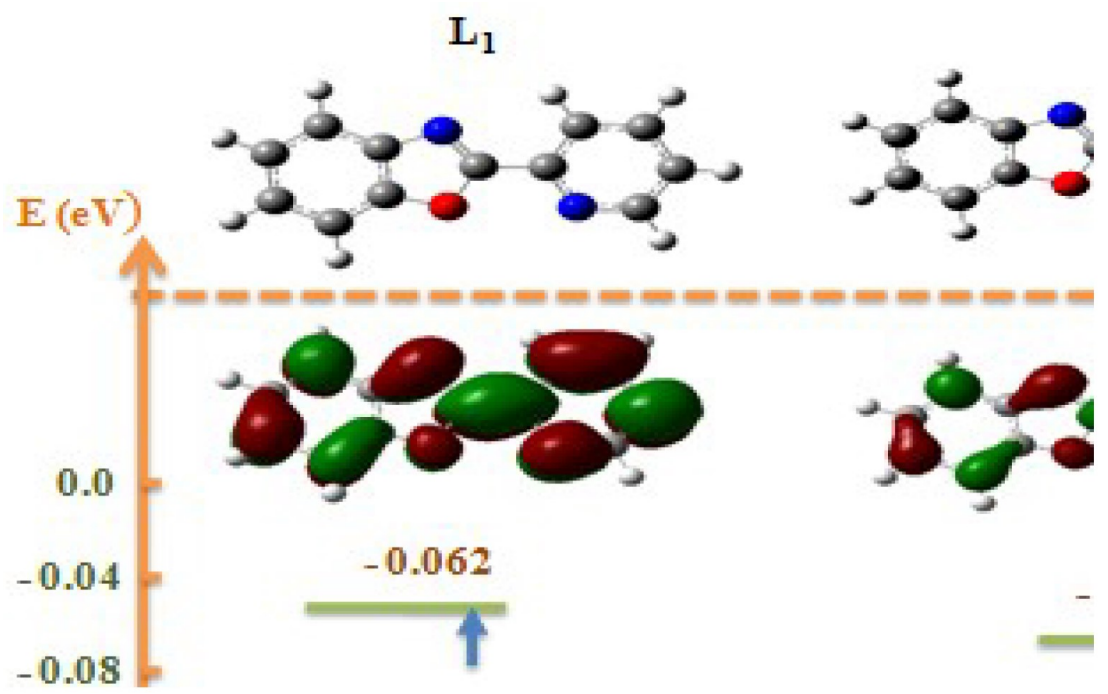

Figure 9. Distribution of the HOMO and LUMO density of $\mathrm{L}_{1}, \mathrm{~L}_{2}$ and $\mathrm{L}_{3}$.

The results presented in Table 7 show that the energy difference is lower, $0.15252 \mathrm{eV}$; therefore, the high reactivity of the inhibitor can allow it to be easily adsorbed onto the mild steel surface leading to an increase of its inhibitory efficiency. 
Table 7. Quantum indices of $\mathrm{L}_{1}, \mathrm{~L}_{2}$ and $\mathrm{L}_{3}$.

\begin{tabular}{|c|c|c|c|c|c|c|c|}
\hline $\begin{array}{c}\text { Quantum } \\
\text { parameters }\end{array}$ & $\mathbf{E}_{\text {номо }}$ & $\mathbf{E}_{\mathbf{L U M O}}$ & $\Delta \mathbf{E}_{\text {(gap) }}$ & $\boldsymbol{\mu}$ & $\mathbf{I}$ & $\boldsymbol{\eta}$ & $\mathbf{\Delta N}$ \\
\hline $\mathbf{L}_{1}$ & -0.22674 & -0.06187 & 0.16487 & 1.2264 & 0.22674 & 0.082435 & 41.58 \\
\hline $\mathbf{L}_{2}$ & -0.22412 & -0.07160 & 0.15252 & 2.6510 & 0.22412 & 0.076260 & 44.93 \\
\hline $\mathbf{L}_{3}$ & -0.23664 & -0.07855 & 0.15809 & 2.1199 & 0.23664 & 0.079045 & 43.28 \\
\hline
\end{tabular}

The dipole moment given in Table 7 is the measurement of the polarity inside the whole molecules ${ }^{43}$. It is usually an index used for predicting the direction of corrosion inhibition. Therefore, it is generally accepted that the adsorption of polar compounds with high dipolar moments onto the mild steel surface should lead to a better inhibition efficiency ${ }^{44}$. The results show that $\mathrm{L}_{2}$ has the highest dipole moment, 2.6510 (debye). Therefore, we can assume that the adsorption of $\mathrm{L}_{2}$ onto the metal surface will be stronger than those of $\mathrm{L}_{1}$ and $\mathrm{L}_{3}$ and therefore the effectiveness of the corresponding inhibition will follow the order $\mu\left(\mathrm{L}_{1}\right)<\mu$ $\left(\mathrm{L}_{3}\right)<\mu\left(\mathrm{L}_{2}\right)$. These results are in good agreement with the experimental results.

The hardness reflects the resistance of a system to changing its number of electrons. A low hardness means that it is easy for the molecule to yield or capture the electrons: $\eta\left(\mathrm{L}_{2}\right)<\eta\left(\mathrm{L}_{3}\right)<\eta\left(\mathrm{L}_{1}\right)$.

The higher the number of electrons transferred, the better the adsorption onto the metal surface is promoted: $\Delta \mathrm{N}\left(\mathrm{L}_{1}\right)<\Delta \mathrm{N}\left(\mathrm{L}_{3}\right)<\Delta \mathrm{N}\left(\mathrm{L}_{2}\right)$. These results may lead to an increased adsorption onto the metal surface and increase the efficiency inhibitors accordingly. In relation to experimental inhibitory efficiency, all descriptors correlate with inhibitory efficiencies.

In relation to the experimental inhibitory efficiency, the calculated descriptors are in good correlation with the inhibitory efficiency for the $\mathrm{L}_{2}$ molecule which has the highest efficiency (94\%).

\section{Conclusions}

This work was devoted to the study of organic benzoxazole inhibitors on the corrosion of mild steel in a $1 \mathrm{M}$ hydrochloric acid medium. This study was carried out by gravimetric and electrochemical methods, both stationary and transient. We can conclude that the studied products are good inhibitors and that their efficiencies reach maximum values at $2 \cdot 10^{-3} \mathrm{M}$. The inhibitory power of the latter follows the order: $\mathrm{L}_{2}>\mathrm{L}_{3}>\mathrm{L}_{1}$.

The adsorption of inhibitors $\mathrm{L}_{1}, \mathrm{~L}_{2}$ and $\mathrm{L}_{3}$ onto the steel surface follows the Langmuir isotherm. The negative values of $\Delta \mathrm{G}^{\circ}$ ads indicate that the absorption of these molecules in the corrosive medium occurs spontaneously onto the steel surface.

The comparative study of the different used methods (gravimetry and methods electrochemistry) shows a very good concordance of the results which confirms the complementarity of these two methods.

Theoretical calculations show that molecules with a small energy gap and a high dipole moment exhibit good inhibitory efficiency. 


\section{References}

1. Wang H, Wang X, Wang H, et al. DFT study of new bipyrazole derivatives and their potential activity as corrosion inhibitors. J Mol Model. 2007;13(1):147-53. Doi: https://doi.org/10.1007/s00894-006-0135-X

2. Zarrok H, Oudda H, El Midaoui A, et al. Some new bipyrazole derivatives as corrosion inhibitors for C38 steel in acidic medium. Res Chem Intermed. 2012;38:2051-63. Doi: https://doi.org/10.1007/s11164-012-0525-x

3. Cruz J, Martinez R, Genesca J, et al. Experimental and theoretical study of 1(2-ethylamino)-2-methylimidazoline as an inhibitor of carbon steel corrosion in acid media. J Electroanal. Chem. 2004;566(1):111-121. Doi: https://doi.org/10.1016/j.jelechem.2003.11.018

4. Wahdan $\mathrm{MH}$, Gomma GK. Effect of copper cation on electrochemical behaviour of steel in presence of imidazole in acid medium. Mater Chem Phys 1997;47(2-3):176-83. Doi: https://doi.org/10.1016/S02540584(97)80048-X

5. Bereket G, Hur E, Ogretir C. Quantum chemical studies on some imidazole derivatives as corrosion inhibitors for iron in acidic medium. J Mol Struct (Theochem). 2002;578(1-3):79-88. Doi: https://doi.org/10.1016/S01661280(01)00684-4

6. Bouklah M, Ouassini A, Hammouti B et al. Corrosion inhibition of steel in $0.5 \mathrm{M} \mathrm{H} 2 \mathrm{SO} 4$ by [(2-pyridin-4-ylethyl)thio]acetic acid. Appl Surf Sci. 2005;250(1-4):50-6. Doi: https://doi.org/10.1016/j.apsusc.2004.12.021

7. Lashkari M, Arshadi MR. DFT studies of pyridine corrosion inhibitors in electrical double layer: solvent, substrate, and electric field effects. Chem Phys. 2004;299(1):131-7.

Doi: https://doi.org/10.1016/j.chemphys.2003.12.019

8. Veloz MA, Martinz IG. Effect of Some Pyridine Derivatives on the Corrosion Behavior of Carbon Steel in an Environment Like NACE TM0177. Corrosion. 2006; 62(4):283-92. Doi: https://doi.org/10.5006/1.3280661

9. Abd El-Maksoud SA. The influence of some Arylazobenzoyl acetonitrile derivatives on the behaviour of carbon steel in acidic media. Appl Surf Sci. 2003;206(1-4):129-136. Doi: https://doi.org/10.1016/S0169-4332(02)011881

10. Wang L. Evaluation of 2-mercaptobenzimidazole as corrosion inhibitor for mild steel in phosphoric acid. Corros Sci. 2001; 43(12):2281-9. Doi: https://doi.org/10.1016/S0010-938X(01)00036-1

11. Popova A, Christov M, Deligeorigiev T. Influence of the Molecular Structure on the Inhibitor Properties of Benzimidazole Derivatives on Mild Steel Corrosion in 1 M Hydrochloric Acid. Corrosion. 2003;59(9):756-64. Doi: https://doi.org/10.5006/1.3277604

12. Popova A, Christov M, Raicheva S, et al. Adsorption and inhibitive properties of benzimidazole derivatives in acid mild steel corrosion. Corros Sci. 2004; 46(6):1333-50. Doi: https://doi.org/10.1016/j.corsci.2003.09.025 
13. Khaled KF. The inhibition of benzimidazole derivatives on corrosion of iron in $1 \mathrm{M} \mathrm{HCl}$ solutions. Electrochim Acta. 2003; 48(17):2493-503. Doi: https://doi.org/10.1016/S0013-4686(03)00291-3

14. Wahdan $\mathrm{MH}$. The synergistic inhibition effect and thermodynamic properties of 2-mercaptobenzimidazol and some selected cations as a mixed inhibitor for pickling of mild steel in acid solution. Mater Chem Phys. 1997; 49(2):135-40. Doi: https://doi.org/10.1016/S0254-0584(96)01925-6

15. Tang LB, Li XM, Si YS, et al. The synergistic inhibition between 8hydroxyquinoline and chloride ion for the corrosion of cold rolled steel in 0.5 M sulfuric acid. Mater Chem Phys. 2006;95(1):29-38. Doi: https://doi.org/10.1016/j.matchemphys.2005.03.064

16. Derridj F, Roger J, Geneste F, et al. Palladium-catalyzed direct heteroarylation of chloropyridines and chloroquinolines. J Organomet Chem. 2009;694(3):455-465. Doi: https://doi.org/10.1016/j.jorganchem.2008.11.032

17. Ben Hmamou D, Salghi R, Zarrouk A, et al. Investigation of corrosion inhibition of carbon steel in $0.5 \mathrm{M} \mathrm{H} 2 \mathrm{SO} 4$ by new bipyrazole derivative using experimental and theoretical approaches $\mathrm{J}$ Environ Chem Eng. 2015;3(3):2031-41. Doi: https://doi.org/10.1016/j.jece.2015.03.018

18. Kaddouri Y, Takfaoui A, Abrigach F, et al. Tridentate Pyrazole Ligands: Synthesis, Characterization and Corrosion Inhibition properties with Theoretical investigations. J Mater Environ Sci. 2017;8(3) 845-56.

19. Khaled KF, Hackerman N. Investigation of the inhibitive effect of orthosubstituted anilines on corrosion of iron in $1 \mathrm{M} \mathrm{HCl}$ solutions. Electrochim Acta 2003;48(19):2715-23. Doi: https://doi.org/10.1016/S00134686(03)00318-9

20. Ebenso EE, Alemu H, Umoren SA, et al. Inhibition of Mild Steel Corrosion in Sulphuric Acid Using Alizarin Yellow GG Dye and Synergistic Iodide Additive. Int J Electrochem Sci. 2008;3(12):1325-39.

21. Singh AK, Quraishi MA. Adsorption properties and inhibition of mild steel corrosion in hydrochloric acid solution by ceftobiprole. J Appl Electrochem. 2011;41:7-18. Doi: https://doi.org/10.1007/s10800-010-0202-y

22. Olen L, Riggs JR, Ray M, et al. Temperature Coefficient of Corrosion Inhibition. Corrosion. 1967;23(8):252-60. Doi: https://doi.org/10.5006/00109312-23.8.252

23. Eddy NO, Ebenso EE, Odiongenyi AO. Corrosion inhibitive properties and adsorption behaviour of ethanol extract of Piper guinensis as a green corrosion inhibitor for mild steel in H2SO4 Afri J Pure \& Appl Chem. 2008;2(11):107-15. Doi: https://doi.org/10.5897/AJPAC.9000049

24. Marsh J. Advanced organic chemistry. 3rd ed. New Delhi: Wiley Eastern; 1988.

25. Ouali I, Hammouti B, Aouniti A, et al. Thermodynamic characterisation of steel corrosion in $\mathrm{HCl}$ in the presence of 2-phenylthieno (3, 2-b) quinoxaline. J Mater Envir Sci. 2010;1(1):1-8.

26. Umoren SA. Inhibition of aluminium and mild steel corrosion in acidic medium using Gum Arabic. Cellulose. 2008;15:751-61. Doi: https://doi.org/10.1007/s10570-008-9226-4 
27. Obot IB, Umoren SA, Obi-Egbedi NO. Corrosion inhibition and adsorption behaviour for aluminuim by extract of Aningeria robusta in $\mathrm{HCl}$ solution: Synergistic effect of iodide ions. J Mater Environ Sci. 2011;2(1):60-71.

28. Fouda AS, El Kaabi SS, Mohamed AK. Substituted phenyl n-phenylcarbamates as corrosion inhibitors for iron in hydrochloric acid. Anti-Corros Methods Mater. 1989;36(8):9-12. Doi: https://doi.org/10.1108/eb020787

29. Saleh JM, Al Haidari YK. Inhibiting Effects of Ethanethiol, Dimethyl Sulfide, and Dimethyl Disulfide on the Corrosion of Stainless Steel (405) in Sulfuric Acid. Bull Chem Soc Jpn. 1989;62(4):1237-45. Doi: https://doi.org/10.1246/bcsj.62.1237

30. Olivares O, Likhanova NV, Gomez B, et al. Electrochemical and XPS studies of decylamides of $\alpha$-amino acids adsorption on carbon steel in acidic environment. Appl Surf Sci. 2006;252(8):2894-909. Doi: https://doi.org/10.1016/j.apsusc.2005.04.040

31. Avci G. Inhibitor effect of $\mathrm{N}, \mathrm{N}^{\prime}$-methylenediacrylamide on corrosion behavior of mild steel in 0.5 M HCl. Mater Chem Phys. 2008;112(1):234-8. Doi: https://doi.org/10.1016/j.matchemphys.2008.05.036

32. Abiola OK, Oforka NC. Adsorption of (4-amino-2-methyl-5-pyrimidinyl methylthio) acetic acid on mild steel from hydrochloric acid solution (HCl)-Part 1. Mater Chem Phys. 2004;83(2-3):315-22. Doi: https://doi.org/10.1016/j.matchemphys.2003.10.001

33. Zarrouk A, Zarrok H, Salghi R, et al. The Adsorption and Corrosion Inhibition of 2-[Bis-(3,5-dimethyl-pyrazol-1-ylmethyl)-amino]-pentanedioic Acid on Carbon Steel Corrosion in $1.0 \mathrm{~m} \mathrm{HCl}$. Int J Electrochem Sci. 2012;7(10):10215-32.

34. Anejjar A, Zarrouk A, Salghi R, et al. Computational and Experimental Evaluation of the Acid Corrosion Inhibition of Carbon Steel by 7-Methyl-2 Phenylimidazo[1,2- $\alpha$ ]Pyridine. Int J Electrochem Sci. 2013;8(4):5961-79.

35. Tebbji K, Faska N, Tounsi A, et al. The effect of some lactones as inhibitors for the corrosion of mild steel in $1 \mathrm{M}$ hydrochloric acid. Mater Chem Phys. 2007;106(2-3):260-7.

Doi: https://doi.org/10.1016/j.matchemphys.2007.05.046

36. El Ouasif L, Merini I, Zarrok H, et al. Synthesis and inhibition study of carbonsteel corrosion in hydrochloric acid of a newsurfactant derivedfrom2mercaptobenzimidazole. J Mater Environ Sci. 2016;7(8):2718-30.

37. Emregul KC, Kurtaran R, Atakol O. An investigation of chloride-substituted Schiff bases as corrosion inhibitors for steel. Corros Sci. 2003;45:2803-17. Doi: https://doi.org/10.1016/S0010-938X(03)00103-3

38. Gaussian 09, Revision A02, Frisch MJ, et al. J Gaussian Inc, Wallingford CT. 2009.

39. Musa AY, Kadhum AH, Mohamad AB, et al. Electrochemical and quantum chemical calculations on 4,4-dimethyloxazolidine-2-thione as inhibitor for mild steel corrosion in hydrochloric acid. J Mol Struct. 2010;969(1-3):233-7. Doi: https://doi.org/10.1016/j.molstruc.2010.02.051 
40. Hackerman N, Snavely Jr ES, Payne Jr. Effects of Anions on Corrosion Inhibition by Organic Compounds. J Electrochem Soc. 1966;113:677-81.

41. Liu WC. Method of evaluating the ionic conductance of polypyrrole films and improvement of ionic conductance of polyethylene oxide-incorporated polypyrrole composite. Mater Chem Phys. 2003;77(3):791-795. Doi: https://doi.org/10.1016/S0254-0584(02)00168-2

42. Sastri VS, Elboujdaini M, Brown JR, et al. Surface Analysis of Inhibitor Films Formed in Hydrogen Sulfide Medium. Corrosion. 1996;52:447-52. Doi: https://doi.org/10.5006/1.3292133

43. Pearson RG. Absolute electronegativity and hardness: application to inorganic chemistry. Inorg Chem. 1988;27:734-40. Doi: https://doi.org/10.1021/ic00277a030

44. Eddy NO, Stoyanov SR, Ebenso EE. Fluoroquinolones as Corrosion Inhibitors for Mild Steel in Acidic Medium; Experimental and Theoretical Studies. Int J Electrochem Sci. 2010;5:1127-50.

45. Ebenso EE, Isabiry DA. Adsorption and Quantum Chemical Studies on the Inhibition Potentials of Some Thiosemicarbazides for the Corrosion of Mild Steel in Acidic Medium. Int J Mol Sci. 2010;11:2473-98. Doi: https://doi.org/10.3390/ijms11062473

46. Ashassi-Sorkhabi H, Asghari E. Effect of hydrodynamic conditions on the inhibition performance of 1-methionine as a "green" inhibitor. Electrochim. Acta 2008;54:162-7. Doi: https://doi.org/10.1016/j.electacta.2008.08.024 